\title{
The influence and strategies of the power companies for participation in
}

\section{the carbon market in China}

\author{
Zhang Xiaoxuan ${ }^{1, \mathrm{a}^{*}}, \mathrm{Ma} \mathrm{Li}^{1, \mathrm{~b}}$, Xue Song ${ }^{1, \mathrm{c}}$ \\ 1.State Grid Energy Research Institute, Beijing 102209, China \\ azhangxiaoxuan@sgeri.sgcc.com.cn, ${ }^{\mathrm{b}}$ mali@sgeri.sgcc.com.cn, ${ }^{\mathrm{c} x u e s o n g @ s g e r i . s g c c . c o m . c n ~}$
}

Keywords: power grid companies, power generation companies, carbon market, impact

Abstract: In China, the power sector is the largest source of emissions, account for about $50 \%$ of $\mathrm{CO}_{2}$ emission nationwide, meanwhile the power sector plays a pivotal and irreplaceable role in promoting low-carbon development. In all seven polite markets, power generation companies are the companies under control. The development of national market has been put on the agenda. It is planned to be built in 2017. the paper analyzes the development of Chinese carbon market and its impact on China's power companies, then some strategies and measures for the power companies to respond to and participate in the carbon market were put forward.

\section{Introduction}

Under the background of global responding to climate change, Carbon emission trading as an important market mechanism has been an inevitable choice of many countries. Several markets of carbon emission permits trade have already been established, such as EU ETS, RGGI of the United States, Japan and any other countries. Chinese Carbon Emission Trading Market is in the period of rapid development. China has conducted seven ETS pilots (Shenzhen, Beijing, Tianjin, Shanghai, Guangdong, Hubei, Chongqing) and the size of market as well as the level of activity is in the world-leading status. The development of national market has been put on the agenda. It is planned to be built in 2017, will cover iron and steel, electricity, chemicals, building materials, paper and non-ferrous metals and other key industries. As the main members of the carbon market, the electricity industry will face major challenges and opportunities, with the rapid development of the carbon market. So, the paper analyzes the development of Chinese carbon market and present strategies and measures for electricity industry to respond to and participate in the carbon market.

\section{Development of carbon emissions trading in China}

China has become the largest carbon emitter and the second-largest economy in the world. Constrained by limited resources and environmental pressures, China must therefore seek an innovative new path of development and upgrade its growth model to a "new normal", and adopting a low-carbon, efficiency-focused path of development. On 30 June 2015, the Chinese government submitted its Intended Nationally Determined Contribution (INDC), detailing its commitment to climate change mitigation and adaptation for the post-2020 period. The specific goals such as carbon dioxide emissions per unit of GDP will lower 60\% to 65\% from 2005 levels and peak carbon dioxide emissions will be achieved by approximately 2030 or sooner as best efforts allow are put forward[1]. The national carbon market will be launched in 2017, and the preparatory work is moving forward rapidly. In the aspect of legislation, the regulations of carbon emissions trading is expected to be introduced in the first half of next year. In terms of accounting methods, 24 
greenhouse gas accounting methods and report guidelines of the key industries such as electricity, steel has been published. In the aspect of pilots, seven provinces and cities (Shenzhen, Beijing, Tianjin, Shanghai, Guangdong, Hubei, Chongqing) carbon trading pilot successively started since 18 June 2013, and the market rules are gradually perfecting. 2015 is the first performance year that seven pilot carbon markets all started, and also the first year of CCER transactions in the carbon market. Up to August 2015, China's carbon market cumulative reached 1.213 billion RMB, about 40.304 million tons Carbon dioxide, including 8.85 million tons of CCER. China's carbon market has been the second largest carbon market in the world.

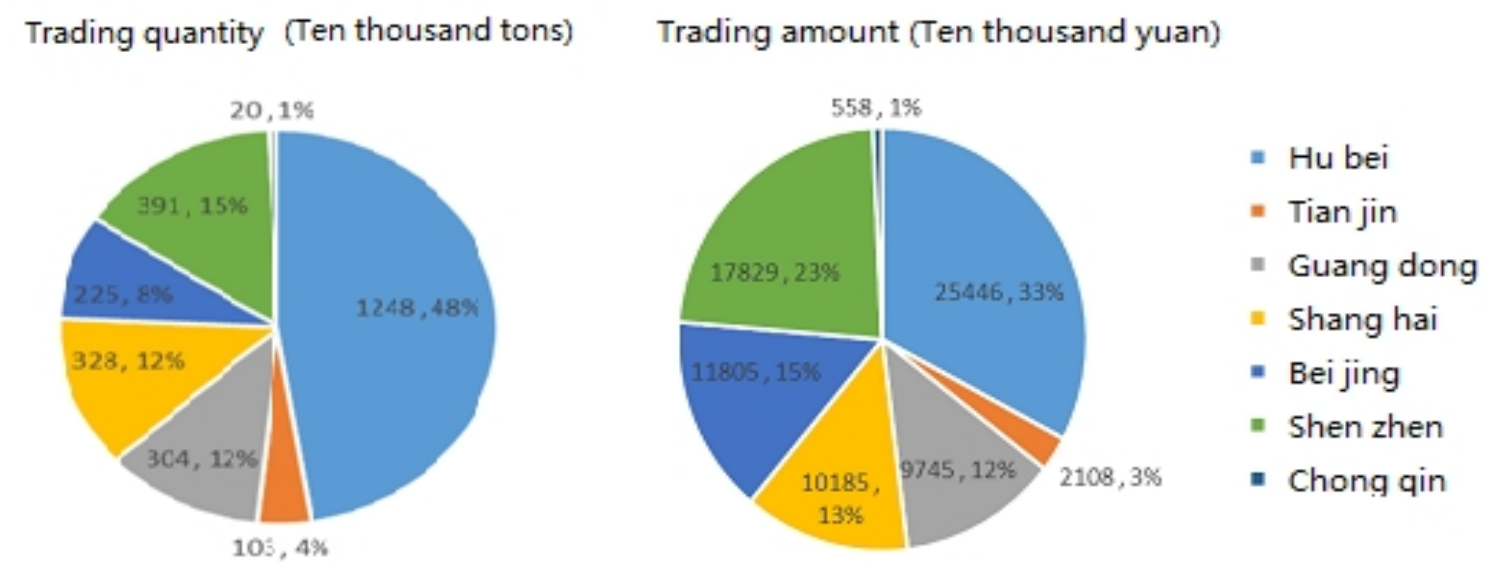

Fig. 1 Trading amount and quantity of China's Carbon Market up to August 2015

\section{The impact of carbon market on China's power companies}

With the development of China's carbon market, the development strategy, management models and profit patterns and so on of the power companies will be greater affected.

For China's power generation companies, first of all, will prompt them to adjust their development strategy, optimize the power-generation investment decision-making, and increase the investment in clean power generation technologies, and so on. The increasing of carbon price will lead power-generation firms to develop more hydropower, wind power and other clean energy power generation capacity in the future, and reduce carbon emissions. Secondly, power generators should change their traditional business model, taking carbon as the assets to operate and manage. The profit pattern of some power generation enterprises will be changed, such as high-efficiency power plant,wind power or photovoltaic power generation enterprises, by selling of carbon emissions rights, may have a huge economic income and become a part of its profits. Thirdly, China's power production is mainly depends on coal-fired power generation, the costs of emission reduction will be added to the power generation cost. As the market price mechanism is established, the relationship of electricity price and carbon price should be considered. Overall, these changes to the power generation companies are both an opportunity and a challenge. For power grid companies, as not the direct source of carbon emissions, they are seldom included in the mandatory emission reduction carbon trading system. But the cap and trade

systems in China may consider the direct and indirect source of carbon emissions at the same time. So, power grid companies may be included in the cap and trade systems. Grid connects power generators and consumers, serve and promote carbon emission reduction of generation side and consumer side[2-4]. With large-scale carbon trading to carry out, in bringing significant opportunities, it also has a significant impact on the aspects of construction, plan, operation and management. Power grid companies face key opportunities and challenges. Firstly, Carbon trading 
will bring power grid companies significant opportunities to accelerate technology and management innovation. Grid companies will try hard to reduce power transmission and distribution losses, that will contribute to construct smart grid, optimize network structure, develop UHV transmission technology, and so on[5]. Secondly, the carbon market will promote the development of wind, solar, hydropower and other clean energy resources, which were relatively concentrated and far away from the the load centers, large-scale and long distances transmission for clean energy and promoting their scale development. Thirdly, in order to adapt to various kinds of low-carbon power's rapid development under the carbon market environment, the dispatch of grid is requested to be more controllable, safety, flexible and robust. With the construction of UHV power grids and national network interconnection, large-scale generation dispatch aimed at energy saving and environmental protection will come true.

\section{The requirements of power companies to participate in carbon markets}

As carbon emission trading more widely, the concept of low carbon development also goes deep in the hearts of people, both power generators and grid companies need to change strategy and management models based on the new situation, and strengthen capacity building of carbon emission statistics, carbon asset management, low-carbon technology innovation and enterprise carbon management.

Firstly, strengthen capabilities of carbon emissions statistics, monitoring and management. Carbon emission statistics, verification and reporting are most important basic work for companies to participate in carbon markets. Therefore, the power companies need to strengthen the statistics and management of carbon emissions data, and establish a complete data collection, accounting and management system, which may provide support for power companies to participate in the carbon market and implement carbon emission reduction.

Secondly, strengthen capabilities of carbon asset management. China Huaneng Group, China Datang Corporation, China Guodian Corporation , China Power Investment Corporation and other power generation companies have set up a special carbon asset management companies.

State Grid Corporation of China has also established a specialized carbon asset management companies. With the development of the domestic carbon trading, particularly the introduction of carbon finance, the contents and methods of carbon asset management will be broaden a lot, and may bring some new profit growth points. So, the power companies need pay attention to and strengthen capacity building of carbon asset management, such as the development, reserves and evaluation of carbon asset, market strategy, investment analysis and other aspects.

Thirdly, strengthen the low-carbon technology innovation and $\mathrm{R} \& \mathrm{D}$ capabilities. In order to decreased the costs of emission reduction and get more space for development, the key is to carry out technological innovation. For power generation companies, the development and application level of wind power, solar power and other low-carbon technologies need to be further enhanced, and carbon dioxide capture and storage technology (CCS) as well. For power grid companies, network technology of large-scale renewable energy, advanced energy storage, smart grid, ultra-high voltage grid and so on need to be further enhanced.

Fourthly, strengthen capacity building of enterprise carbon management. Along with the development of the carbon market, when the power companies develop strategic planning should consider the carbon emissions constraints, study the development strategies and investment plans under the carbon market environment, taking into account the impact of carbon prices ,carbon asset management and other issues. Carbon emissions reduction and carbon emissions trading will throughout the whole process that include planning, investment, construction, technical innovation, 
operation and management of power companies. So, it need to set up establish a management system, and strengthen coordination and cooperation of the business sector to enhance corporate carbon management.

\section{Conclusion}

China's future development is clearly trending toward low-carbon growth, China will face a number of challenges in achieving its INDC targets. As the largest source of carbon emissions, the power sector need to play more important role in promoting low-carbon development. The development of national market has been put on the agenda. It is planned to be built in 2017. The power companies participate in carbon emissions trading, face major challenges and opportunities. From the perspective of the power industry, carbon emission trading will promote low carbonization of power supply and consume, have far-reaching impact of the power structure and layout, and promote the advance of technology. In addition, the development of electricity trading and electricity market will also be some changes and adjustments. Therefore, the power companies need to paid adequate attention, strengthen capacity building, and to be ready for change.

\section{References}

[1] Information on http://www.ncsc.org.cn/article/yxcg/ir/201507/20150700001490.shtml.

[2] Fu liwen, Analysis on Low-carbon benefits of Smart Grid, Electric Power Construction, 32(2011)51-55.

[3]EPRI. The green grid:energy savings and carbon emissions reductions by smart $\operatorname{grid}[\mathrm{R}]$. Technical Update, 2008.

[4]Wu peng, Jiang liping (2009). Comprehensive benefits evaluation of smart grid. China Power Enterprise Management. 7 (2009)35-37.

[5]State Grid Energy Research Institute. Strong and smart grid in promoting low carbon development.Beijing,2010. 